\title{
Kernos
}

Revue internationale et pluridisciplinaire de religion grecque antique

$1 \mid 1988$

Varia

\section{Pierre HADOT, Exercices spirituels et philosophie antique}

André Motte

\section{OpenEdition \\ Journals}

Édition électronique

URL : http://journals.openedition.org/kernos/138

DOI : 10.4000/kernos. 138

ISSN : 2034-7871

\section{Éditeur}

Centre international d'étude de la religion grecque antique

Édition imprimée

Date de publication : 1 janvier 1988

ISSN : 0776-3824

\section{Référence électronique}

André Motte, «Pierre HADOT, Exercices spirituels et philosophie antique », Kernos [En ligne], 1 | 1988, mis en ligne le 12 avril 2011, consulté le 22 septembre 2020. URL : http://journals.openedition.org/kernos/ 138 ; DOI : https://doi.org/10.4000/kernos.138 
Bernard C. DIETRICH, Tradition in Greek Religion, Berlin, de Gruyter, 1986, XVI+213 p., 16x23,5 cm. Prix : DM 112.

Dans la controverse sur l'unité ou la disparité des civilisations minoenne et continentale, l'A. prend clairement position en étudiant la période créto-mycénienne comme un tout cohérent et original (chap. I : The Religious Unity of Minoans and Mycenaeans; chap. II : Tradition in the History of Greek Religion). Le troisième chapitre envisage le concept grec de la divinité et les nombreux changement survenus à la suite du traitement épique et des mutations politico-sociales, tandis que la quatrième et dernière partie étudie le culte d'Apollon à Kourion de Chypre, bel exemple du conservatisme religieux de lîle. La conclusion rassemble en un tout cohérent les résultats de démarches parfois fort diverses d'un chapitre à l'autre. La bibliographie est abondante et bien à jour.

Sous le signe de la «tradition» sont donc regroupées de nombreuses pratiques, en de nombreux endroits et à l'égard de nombreuses divinités. Sans avoir définitivement résolu un problème toujours reposé, l'A. en fournit une présentation séduisante.

Vinciane PIRENNE-DELFORGE

Pierre HADOT, Exercices spirituels et philosophie antique, 2e édition revue et augmentée, Paris, Etudes augustiniennes, 1987, 254 p., $16 \times 24,5 \mathrm{~cm}$.

Cette édition ajoute à la précédente (ibidem, 1981, 206 p.) trois études nouvelles, dont une est inédite ( Un dialogue interrompu avec Michel Foucault»), des addenda et corrigenda, une postface, ainsi qu'une bibliographie sommaire. Le précieux index des thèmes qui termine le volume se trouve aussi enrichi.

Qu'elles aient une portée générale ou qu'elles soient consacrées à un auteur (Socrate, Marc-Aurèle), ou à une notion particulière (l'idée de conversion, la théologie négative), ces études convergent vers un même but : montrer que la philosophie antique ne se réduisait pas à un discours, à un ensemble de théories enseignées dans des cours ou dans des livres, mais qu'elle fut aussi, et plus fondamentalement, un mode de vie, un art de vivre, une manière d'être. «Une attitude existentielle fonde l'édifice dogmatique» (p. 64). C'est en tant qu'exercice spirituel que la philosophie a pu être assimilée par le christianisme; celui-ci n'hésitera pas à se présenter lui-même, en ce sens, comme la vraie philosophia. En retrouvant son autonomie, la philosophie moderne a principalement retenu l'aspect théorique de la démarche, lequel tend encore à prévaloir de nos jours.

Les exercices spirituels des philosophes anciens comportaient déjà bon nombre d'éléments religieux. Mais, mis à part le chapitre qu'il consacre à la théologie négative, l'A. ne fait qu'évoquer au passage cette importante dimension. Si son remarquable ouvrage mérite néanmoins d'être signalé ici, c'est qu'il ouvre des voies nouvelles, qui pourraient s'avérer fécondes, à l'étude de la religion deś philosophes de l'Antiquité.

André MOTTE 